\title{
A POTENCIALIDA DAS REDES SOCIAIS NA PROPAGAÇÃO DE INFORMAÇÕES VINCULADAS AO TURISMO UM ESTUDO DA FANPAGE: "A ARTE DO TURISMO E DA HOTELARIA".
}

Leonardo Giovane Moreira Gonçalves, Fabio Luciano Violin.

Universidade Estadual Paulista - UNESP, curso de Turismo, Rosana, SP. E-mail: leonardo.giovane@hotmail.com

\section{RESUMO}

A Era Digital instituiu novos métodos de comunicação e marketing, a globalização, por sua vez, aproximou os que estavam longe e também popularizou a informação. $O$ advento da internet $\mathrm{e}$ das mídias sociais ofertou as grandes, medias e pequenas empresas o benefício do estreitamento em massa dos laços com os consumidores. Além disso, é notória uma expansão gradativa de fanpages no facebook que tratam de diversos temas, em especial, as que tratam de turismo vêm ganhando seu público em meio a tantos usuários. Dessa forma, o presente artigo buscou por meio de referencial teórico, bem como livros, sites e artigos, que versam sobre a temática de mídias digitais e marketing digital, expor a potencialidade das redes sociais, em especial o Facebook, na propagação de informações vinculadas ao turismo, usando como objeto de estudo as publicações da fanpage do blog A Arte do Turismo e da Hotelaria.

Palavras chave: Redes sociais; Marketing Digital; Facebook; Fanpages; Comunicação.

THE POTENTIAL OF SOCIAL MEDIA IN SPREADING INFORMATION RELATED TO TOURISM A STUDY OF FANPAGE: "THE ART OF TOURISM AND HOSPITALITY".

\begin{abstract}
The Digital Age instituted new communication and marketing methods, globalization, in turn , approached those who were far away and also popularized the information. The advent of the Internet and social media has offered large, medium and small companies the benefit of the mass closer ties with consumers. Moreover, it is evident a gradual expansion fanpages on facebook dealing with various topics, especially those dealing with tourism are gaining your audience among many users. Thus, this article sought through theoretical as well as books, websites and articles focusing on the topic of digital media and digital marketing, display the potential of social networks, especially Facebook, the spread of linked information tourism, using as study object the blog fanpage publications the Art of Tourism and Hospitality .

Keywords: Social networks; Digital Marketing; Facebook; Fanpages; Communication.
\end{abstract}




\section{INTRODUÇÃO}

$\mathrm{Na}$ sociedade contemporânea as mídias sociais ganham a cada dia mais espaço no cotidiano das famílias. Com o advento da tecnologia, a globalização e popularização da internet, o número de pessoas "logadas" (conectadas) em redes sociais é inquietante.

A internet tornou-se o veículo com maior poder de propagação de informações e surpreendente capacidade de atingir segmentos e nichos antes caros e de difícil aceso. Segundo Garattoni e Roxo (2009) cada individuo visualiza "mais de 90 propagandas por dia, todos os dias" e, os anúncios que são veiculados pela internet assumem mais da metade deste valor.

Nesses termos pode-se inferir que estratégias refinadas vinculadas ao Marketing digital são indispensáveis dadas as austeras alterações do ambiente em que as organizações operam, sejam elas suscitadas pela concorrência, alterações no comportamento do consumidor, mudanças socioambientais, tecnológicas ou dezenas de outras possibilidades que acabam por interferir no modo de realização dos processos cotidianos. Ressalta-se que esse marketing digital faz menção ao universo dos anseios e das necessidades humanas, mas também, o numero de propagandas sobre o turismo também possui uma porcentagem significativa.

A internet tornou-se ambiente propicio para que organizações de todos os portes e localizações geográficas estreitassem sua abordagem com consumidores reais e potenciais de modo amplo, rápido e irrestrito.

Além das propagandas e anúncios, é visível que noticias colunas, charges, vídeos, imagens, frases e outros, relacionados ao turismo, também possuem ampla divulgação nas mídias sociais, dado a grande quantidade de blogs, sites, fanpages, perfils, twiters e outros afins que versam a respeito da temática.

Dessa forma, o presente artigo analisou a potencialidade das redes sociais, em especial o Facebook, na propagação de informações vinculadas ao turismo, tendo como objeto de análise a fanpage do blog A Arte do Turismo e da Hotelaria.

\section{METODOLOGIA}

Os procedimentos metodológicos envolveram revisão bibliográfica caracterizando assim a primeira forma de discussão e apresentação do corpo teórico de informações. Por sua natureza o estudo apresenta-se como de natureza qualitativa ao discutir em profundidade um único objeto.

Também apresenta natureza quantitativa ao tratar estatisticamente alguns dados provenientes da discussão. 
As ferramentas disponibilizadas pela página em análise oferecem as ferramentas de projeção estatística e por seu contexto a natureza do estudo configura-se como exploratória e descritiva ao permitir a ampliação e contextualização ainda que inicial de elementos pertinentes ao contexto do estudo. A pesquisa não envolveu dados extraídos de pessoas.

\section{RESULTADOS}

A fanpage A Arte do Turismo e da Hotelaria é proveniente de um blog, que possui o mesmo nome, criado em 28 de junho de 2013 e a fanpage foi criada no dia 15 de fevereiro de 2014.

O blog ${ }^{1}$ surgiu como um diário de classe de um curso técnico em hospedagem realizado por seu autor e, após o término do mesmo, o mesmo continuou sendo alimentando com opiniões e informações sobre o turismo e a hotelaria, e atualmente possui aproximadamente 25.800 visualizações. Assim, em um curto espaço de tempo foi possível observar o aumento repentino das visualizações, deste modo o responsável decidiu expandir o blog para uma fanpage.

A fanpage $e^{2}$ nos seus primeiros meses começava a adquirir publico e ter seus primeiros seguidores. Atualmente ela detém aproximadamente 7.000 fãs que ficam inteirados de noticias, inovações, curiosidades, vagas de empregos e outros assuntos que versam sobre a temática do turismo e da hotelaria que são conteúdos produzidos pela própria fanpage ou compartilhada de outros sites, blogs, fanpages e autores.

Com o intuito de realizar análise amostral da potencialidade, bem como o alcance, das publicações da fanpage do blog A Arte do Turismo e da Hotelaria, foi programada durante a semana do dia 19 de julho ao dia 25 de julho, publicações na página.

Utilizando mecanismos existentes no próprio sistema do Facebook, foi possível mensurar a amplitude das publicações individuais e, em especial, o total de acessos, curtidas, comentários e compartilhamentos realizados no período observado.

Deste modo, conforme explanado na Figura 1, o alcance das publicações semanais foi de 70.116 pessoas no alcance total, sendo que são somadas as publicações da página e o número de acesso à página e, cerca de 69.933, que representam o alcance das publicações. Salienta-se que as porcentagens em verde fazem referencia a diferença em relação à semana anterior, que em ambos está a pouco mais de $41 \%$.

\footnotetext{
${ }^{1}$ Link para o blog: http://aartedoturismo.blogspot.com.br/

${ }^{2}$ Link para a fanpage: https://www.facebook.com/aartedoturismo 
70.116 Alcance total

$\Delta 41,6 \%$ desde a semana passada

\subsection{3}

Alcance da publicação

- $41,7 \%$

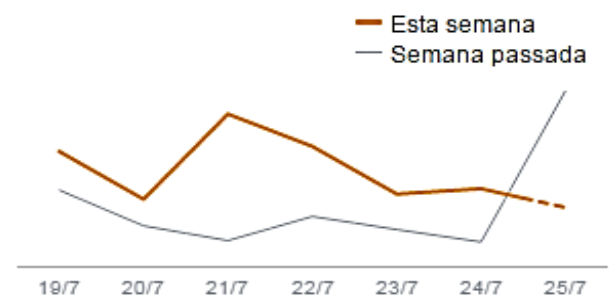

Figura 1. Alcance das Publicações

O envolvimento dos internautas com as publicações, que no decorrer da semana teve a participação de 6.251 pessoas, cerca de $27,3 \%$ superior a semana anterior. O envolvimento se baseia pela curtida nas publicações, comentários, compartilhamentos e o clique nos links que os internautas realizam.

Salienta-se, que para realização dessa amostra, foram publicadas noticias, informações, vagas de emprego, dicas e outros temas relacionados ao turismo, em horários determinados, bem como às $8 \mathrm{~h}, 11 \mathrm{~h}, 15 \mathrm{~h}$ min e às $19 \mathrm{~h} 30 \mathrm{~min}$, horários estes que foram aplicados a todos os dias da semana. Das 28 publicações realizadas na fanpage no decorrer da semana, 3 obtiveram um numero expressivo de curtidas, comentários, compartilhamentos e acessos. A primeira publicação faz referência a uma imagem de humor sobre a profissão, que mostrava os 10 motivos para se namorar um turismólogo (a) e, alcançou cerca de 29.392 pessoas, teve 414 curtidas e 208 compartilhamentos.

Já a segunda publicação faz referencia a uma pesquisa que expõe 10 sites que trocam hospedagem e alimentação por trabalho e cultura, assim, a publicação conseguiu obter 10.668 pessoas alcançadas, 214 curtidas e 100 compartilhamentos. A publicação 3 faz referencia a uma noticia de que a Itália tem o 1 을 hotel gerenciado por jovens com síndrome de Down, conseguindo alcançar 10.356 pessoas, 222 curtidas e 109 compartilhamentos.

\section{DISCUSSÃO}

Com o advento da era digital a concepção de comunicação se alterou. Segundo Mota (2001, p. 153), “a era digital traz mudanças revolucionárias na comunicação, ocasionando profundas mudanças comportamentais nos indivíduos, principalmente no que se refere ás atitudes de compra e venda dos consumidores". 
O comportamento dos indivíduos se altera drasticamente, pois os tipos de mídias se reformulam e se tornam populares para grande parte do mundo podendo ser entendida como:

[...] um título ligado ao tipo e formato de comunicação que ocorre ao redor de todos nós. Ás vezes consciente, outras subconscientemente, na comunicação formal e informal tomamos conhecimento do espaço que nos cerca. Como parte dessa conscientização, formulamos ideias e atitudes que levam a uma interpretação do nosso meio (NIELSEN, 2002, p.250).

Dessa forma, a mídia pode ser dividida em mídia inscrita e impressa, bem como impressões em papeis, folders, flyers Entre outros nesse contexto aponta-se a existência da mídia projetiva, que pode ser entendida como uma rede de sinais projetados em celulares, computadores, painéis e outros; além da mídia ambiental, que pode ser simplificada como um espaço ou corpo utilizado para veiculação de uma mensagem, basicamente outdoor, placas e similares (Vaz, 2002, p. 215).

Utilizando este princípio, a internet está inserida na categoria de mídia projetiva. Para efeito de erudição, a "internet pode ser definida como uma rede de computadores composta por milhões de hosts de organizações ao redor do mundo transportando dados pelos computadores". (Williams, 1996, apud, Nielsen, 2002, p. 36).

A internet, de forma simplificada, permite aos usuários o acesso à informação em poucos segundos e no mundo inteiro, além disso, a derruba as "fronteiras" e suscita a queda das barreiras físicas e geográficas além da língua, dos conceitos e outros elementos que apontam para a revolução criada por esse instrumento.

Com o intuito de agrupar todas as inúmeras possibilidades de utilização da internet surgem as mídias sociais que pode ser conceituada como:

As mídias sociais são espaços de interação entre usuários. São considerados exemplos de mídias sociais: blogs, microblogs (Twitter), redes sociais (Facebook), fóruns, e-groups, instant messengers, wikis, sites de Compartilhamento de conteúdo multimídia (YouTube, Flickr, Slide Share, Vimeo) (QUINTANILHA,2015, s/d).

Assim como as mídias sociais, as ferramentas da internet passam, também, a ser mecanismos de Marketing para empresas e indivíduos, que desejam vender seus produtos, divulgar ações, marcar encontros, realizar promoções, lançar produtos e outros. Aponta-se que:

A internet pode ser tão colorida quanto uma revista, pode ter movimento como na televisão ou nos filmes e pode transmitir som com a qualidade de um estéreo ou rádio. $E$, com exceção dos custos de conexão, provavelmente ele é uma das formas de mídia de mais baratas que existem (NIELSEN, 2002, p. 40) 
Por essa facilidade a internet vem ganhando espaço nas estratégias publicitárias de muitas empresas, dado o seu baixo custo para veiculação de informação. Além do baixo custo, atualmente, segundo o Jornal Folha de São Paulo (2014), ela também possui cerca de 3 bilhões de usuários, aproximadamente $40 \%$ da população mundial tem acesso a rede.

Em 2012, segundo a União Internacional de Telecomunicações- UIT foi constatado mais de 1 bilhão de pessoas possuem perfis nas mídias sociais, somente o Facebook teria 901 milhões de usuários (TERRA, 2012). Segundo o levantamento da Pew Research Center (MARTINS, 2015), o Facebook, criado por Mark Zuckerberg, em 2004, contabilizou neste ano cerca de 1.44 bilhão de usuários em todo o mundo. Dessa forma, é possível compreender perceber o crescimento no lapso de tempo decorrido de 2012 a 2015, cabendo à análise de que a rede tende a se expandir nos próximos anos.

Segundo o IBGE (EBC, 2015), no Brasil, em 2015, cerca de 85,6 milhões de brasileiros tem acesso a internet, aproximadamente $49,4 \%$ da população. Quando se trata de redes sociais, no ano de 2014, o Brasil marcou cerca de 61,2 milhões de usuários no Facebook, ocupando o 3 lugar no Ranking mundial (Uol, 2014).

Assim, com um baixo custo de divulgação e um grande público conectado, as empresas vêm investido cada vez mais nas mídias sociais, em especial na rede social do Facebook. Como uma visão mercadológica, de venda de produtos a usuários, o Facebook se tornou um mecanismo propagador de informações, ideias, noticias e outros, ou seja, uma ferramenta de massa, que por sua vez possui a comunicação como maior vertente.

Conforme observado nas estatísticas expostas anteriormente, o acesso à internet se popularizou. Atualmente as pessoas tem acesso nos computadores, tablets, celulares e outros veículos, assim como a internet o Facebook se popularizou, se transformando em elemento pertinente ao cotidiano da vida moderna em sociedade, bem como a detenção de um aparelho celular. Desse modo:

O Facebook deixou de ser um espaço somente de relações sociais/pessoais para se transformar também em um espaço de negócios. A comunicação mercadológica sofreu mudanças drásticas com o boom dessas mídias sociais. O comunicar deixou de ser função de um profissional da área para fazer parte de um meio em que todos têm o mesmo poder, poder de informar, de criticar, opinar e divulgar (COSTA, 2012, p.5).

O fato da popularização da comunicação possuir duas vertentes de análise: a primeira se caracteriza pelo beneficio da comunicação com pessoas distantes e entre grupos; a segunda, 
adentrando no âmbito da informação, com o grande numero de postagens e informações na rede, o caráter de autenticidade se perde, pois todos são produtores de conteúdo.

Entretanto, ressalta-se que neste universo de pessoas conectadas ao facebook, cada uma delas possui um estilo de vida, cultura, religião e outros fatores, que a conduz a procurar diferentes tipos de coisas na rede social. Pode-se afirmar que as redes sociais são:

[...] antes de tudo, relações entre pessoas, estejam elas interagindo em causa própria, em defesa de outrem ou em nome de uma organização, mediadas ou não por sistemas informatizados; são métodos de interação que sempre visam algum tipo de mudança concreta a vida das pessoas, no coletivo e/ou nas organizações participantes (AGUIAR, 2007, p.2).

Dessa forma, entende-se, que as informações veiculadas no facebook atingem um público especifico, e segmentado, pois o mesmo, assim como os outros recursos e plataformas da internet, disponibilizam aos usuários informações e publicidades relacionadas ao seu perfil e aos seus conteúdos acessados na internet. Por sua vez, o próprio usuário pode escolher que tipo de postagens ele quer ter acesso na sua time line (linha do tempo), ou seja, o usuário pode "curtir" as fanpages que mais Ihe agrada e assim ter acesso as suas postagens.

Portanto, entende-se que por mais que o universo de usuários seja grandioso, as empresas tem acesso ao seu publico potencial, dado que o mesmo manifestou interesse diretamente ou indiretamente pelo conteúdo.

Isso ocorre, com as publicações relacionadas ao turismo, que também possuem uma parcela significativa dos usuários do Facebook pode-se dizer que:

Mais de $60 \%$ dos turistas recorrem à internet para tomar decisões: buscar inspirações no planejamento das viagens a lazer ou negócios, garantir as melhores reservas (comparar preços), procurar indicações de locais para ficar e conhecer durante a viagem (experiências prévias), etc. (VIEIRA, 2014, p. 23).

Boa parte deste público procura tais informações em páginas relacionadas ao turismo, hotelaria e eventos, assim como afirma a pesquisa da ComScore (Vieira, 2014), que em "2012, um em cada três usuários da internet visitou sites de viagem (três vezes mais do que em 2009). Só em julho 2014, cerca de 16,5 milhões de brasileiros acessaram páginas nacionais desse tipo".

Neste emulo insere-se a importância das páginas e fanpages para a formatação da viagem, como no caso da fanpage A Arte do Turismo e da Hotelaria, na qual seu publico alvo divide-se em estudantes e formados em hotelaria e/ou turismo, viajantes, turistas e simpatizantes pela temática e, produz e compartilham conteúdos sobre destinos, novidades, informações, curiosidades, humor e entretenimento sobre turismo e hotelaria. 


\section{CONSIDERAÇÕES FINAIS}

A evolução tecnológica, e em especial a popularização da internet e das mídias sociais, tem de certa forma, obrigado empresas a se adequarem aos anseios dos consumidores, adotando assim, novos mecanismos de divulgação e analisando propostas do marketing digital.

Quando se enfatiza os novos consumidores e o turismo, observa-se que é crescente o numero de pesquisas sobre destinos turísticos e, além disso, o consumo de informações, curiosidades, inovações e, também, outros assuntos que abordam a temática do turismo.

Quando se analisa dos dados homologados no decorrer de uma semana na fanpage A Arte do Turismo e da Hotelaria, observa-se que em um curto período de tempo uma única página, considerada de porte médio por conta do número de fãs, consegue alcançar, mas de 70 mil pessoas. Faz-se necessário ressaltar, que esse alcance se deu gratuitamente e que em nenhum momento a página fez uso de publicações patrocinadas para aprimorar o desempenho dos dados.

Portanto, pode-se afirmar que dada à facilidade do acesso, o preço e o público alcançado, a internet vem se tornando mecanismo capaz de levar a informação, bem como vender produtos e serviços, a qualquer parte do mundo e a qualquer pessoa, desde que essa tenha acesso à internet.

Desse modo, o marketing digital, tendo uma amplitude maior nas redes sociais, é um novo nicho de mercado que vem conquistando e diminuindo as distâncias a cada dia, de informação e publico e, de produto e comprador.

\section{REFERÊNCIAS}

AGUIAR, S. Redes Sociais na Internet: Os desafios à pesquisa. Rio de Janeiro, 2007.

COBRA, M. Marketing de Serviços: turismo, lazer e negócios. 2. Ed. São Paulo: Cobra, 2001.

COSTA, N. M. da S. O facebook como ferramenta de comunicação da marca Origens. UVV, 2012. Disponível em <http://www.uvv.br/edital_doc/O\%20FACEBOOK\%20COMO\%20FERRAME NTA\%20DE\%20COMUNICA\%C3\%87\%C3\%830\%20DA\%20MARCA\%20ORIGENS. pdf> Acesso em: 13 de jul. de 2015.

EBC, P. Acesso a internet chega a 49.9\% da população brasileira. Portal EBC. 29 de abr. de 2015. Disponível em <http://www.ebc.com.br/tecnologia/2015/04/acesso-internet-chega-494-da-populacao-brasileira> Acesso em: 14 de jul. de 2015.

FOLHA. Internet já tem 3 bilhões de usuários no mundo, diz ONU. Jornal Folha de São Paulo. 25 de nov. de 2014. Disponível em <http://www1.folha.uol.com.br/tec/2014/11/1553088-internet-ja-tem-quase-3bilhoes-de-usuarios-no-mundo-diz-onu.shtml> Acesso em: 14 de jul. de 2015.

GAROTTONI, B; ROXO, E. Neuro propaganda. Revista Super Interessante, e. 268, 2009. Disponível em < http://super.abril.com.br/ciencia/neuro-propaganda>. Acesso em: 08 de jun. de 2015.

NIELSEN, C. Turismo e Mídia: construção e destruição de destinos turísticos.São Paulo: Contexto, 2002. 
MATIAS, L. Facebook revela total de usuários de WhatsApp, Instagram, vídeos e mais. G1, Techtudo. 24 de abr. de 2015. Disponível em <http://www.techtudo.com.br/listas/noticia/2015/04/facebook-revela-totalde-usuarios-de-whatsapp-instagram-videos-e-mais.html> Acesso em: 14 de jul. de 2015.

MOTA, K. C. N. Marketing turístico: promovendo uma atividade sazonal. São Paulo: Atlas, 2001.

QUINTANILHA, P. $O$ que são mídias sociais?. Disponível em <http://www.pedroquintanilha. com.br/midiassociais/o-que-sao-midias-sociais/> Acesso em: 14 de julho de 2014.

TERRA. Mundo tem 1 bilhão de usuários, diz estudo. Terra. 14 de mai. de 2012. Disponível em <http://tecnologia.terra.com.br/internet/mundo-tem-1-bilhao-de-usuario,

130bfe32cdbda310VgnCLD200000bbcceb0aRCRD.html> Acesso em: 14 de jul. de 2015.

UOL. Facebook tem 1,23 bilhão de usuários mundiais; 61,2 milhões são do Brasil. UOL Noticias. 03 de fev. de 2014. Disponível em <http://tecnologia.uol.com.br/noticias/afp/2014/02/03/facebook-emnumeros.htm> Acesso em: 14 de jul. de 2015.

VAZ, G. N. Marketing turístico: receptivo e emissivo: um roteiro estratégico para projetos mercadológicos públicos e privados. São Paulo: Pioneira Thomson Learning, 2002.

VIEIRA, D. Turismo online: o comportamento do turista na internet. Consumidores digitais. 2014. Disponível em < http://www.consumidoresdigitais.com.br/turismo-online-o-comportamento-turista-nainternet/> Acesso em: 14 de jul. de 2014. 